\title{
Modulation of la and Photoreactive Antigen on Antigen-Presenting Cells: Fun with a Photoprobe ${ }^{1}$
}

\author{
David W. Thomas, ${ }^{2}$ Linda Eades, Cheryl Wilson, and Maxine J. Solvay \\ Department of Microbiology and Immunology, The University of Michigan Medical School, \\ Ann Arbor, Michigan 48109-0010
}

Received June 17, 1985; accepted August 6, 1985

\begin{abstract}
To identify the antigen-specific recognition complex containing elements from $T$ cells and antigen-presenting cells (APC), a photoactivatable antigen system was developed which could potentially crosslink the complex during the specific cellular responses. In this paper we describe the devclopment of this system using murine T-cell hybridomas responding to stimulator cells chemically conjugated with $N$-hydroxysuccinimidyl 4-azidobenzoate (HSAB) and genetically restricted by $\mathbf{I}-\mathrm{A}^{\mathrm{d}}$. In initial experiments it was found that several I-A $\mathrm{A}^{\mathrm{d}}$-positive B-cell lines were

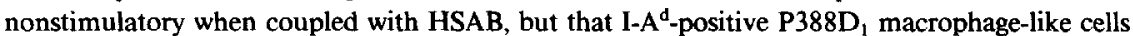
were efficient stimulators of $\mathrm{HSAB}$-specific T-cell responses. These results suggested that the relevant HSAB coupled surface structure was not likely $\mathrm{I}-\mathrm{A}^{\mathrm{d}}$. To substantiate this point, la-positive or Ianegative $\mathrm{P}_{388 \mathrm{D}}$ cells were initially coupled with $\mathrm{HSAB}$ and the expression of Ia was modulated by the addition and withdrawal of Con A-stimulated spleen cell supernatant fluid through several days of culture. Under these conditions, efficient stimulation was only observed when Ia was expressed, although the HSAB antigen was continuously present. In other experiments it was found that exposure of HSAB-coupled APC to light selectively eliminated their stimulatory capacity for HSAB-specific $T$ hybridomas, suggesting that the light-induced crosslinking by HSAB directly eliminates the antigenic determinant. This antigen system allows a unique opportunity to manipulate the antigen during specific cellular interactions, and to introduce covalent crosslinking of the specific antigen recognition complex that may allow its isolation and characterization.

(c) 1985 Academic Press, Inc.
\end{abstract}

\section{INTRODUCTION}

It was initially thought that macrophages were unique in their ability to stimulate specific T-cell responses. This was in part due to their ability to process and present antigens and to produce several costimulator factors, such as interleukin 1 (1). Subsequently, however, a number of different cell types, including dendritic cells, Langerhans cells, B cells, and a variety of cell lines have also been shown to serve as stimulator cells (2-5). Thus, the ability to process and present exogenous antigens is not a unique property of macrophages and this function can be performed by a variety of other cell types. The only apparent common feature of these different cells is that to be stimulatory they must express Ia antigens. This is particularly evident in the

\footnotetext{
'This work was supported by USPHS Grant AI-19273.

${ }^{2}$ Recipient of USPHS Research Career Development Award AI-00532, and to whom correspondence should be addressed.
} 
recent report by Malissen et al. (6) in which murine fibroblasts transfected with Ia genes and cxpressing Ia antigens could present soluble protein antigen to $\mathrm{T}$ cells. It would thus seem that the ability to process and present exogenous antigens is a common feature of lymphoid and nonlymphoid cell types, providing that Ia antigen is expressed. One implication of these findings is that Ia is somehow involved in the processing mechanism itself, or simply binds small antigenic peptides resulting from a ubiquitous cellular catabolic process $(7,8)$. Thus, some of the major questions remaining to be resolved concerning stimulator cells are: (1) Can all Ia-positive cell types from diverse sources present all antigens, or do some cell types present only particular types of antigens? (2) What is the nature of the association between exogenous antigens and Ia, and how do T-cell receptors interact with these determinants? In this report these two questions were addressed using $\mathrm{T}$-cell hybridomas reactive to stimulator cells that had been chemically conjugated with the antigen $N$-hydroxysuccinimidyl 4 -azidobenzoate (HSAB). ${ }^{3}$ It was found that not all la-positive cell types were stimulatory following HSAB conjugation, suggesting that there may be diversity in stimulator cell requirements. In addition, it is also shown that the relevant antigen in this system is a nonIa membrane structure coupled with HSAB, and that Ia and antigen can be independently modulated. The utility of this system is that the HSAB antigen is photoreactive, and exposure of HSAB-coupled cells specifically eliminates T-cell recognition. This experimental approach should allow definition of the cellular components involved in T-cell antigen recognition through selective crosslinking of those structures in proximity to the antigen.

\section{MATERIALS AND METHODS}

Animals. All mice and rats used in these experiments were bred and maintained in the animal facility at the University of Michigan Medical School.

T.Cell hybridomas. Bab. $14\left(\mathrm{H}-2^{\mathrm{d}}\right)$ mice were immunized in the footpads with 50 $\mu \mathrm{l}$ of $50 \mu \mathrm{g}$ of HSAB (Pierce Chemical Co., Rockford, Ill.) emulsified in Complete Freunds Adjuvant (CFA, Difco Laboratories, Detroit, Mich.), or with CFA alone, and the popliteal lymph nodes removed 2 weeks later. Lymph node cells from CFA-immune mice were cultured with $50 \mu \mathrm{g} / \mathrm{ml}$ of PPD (Connaught Medical Research Labs, Ontario, Canada) and those from HSAB-immune mice treated with HSAB as follows. HSAB at $10 \mathrm{mg} / \mathrm{ml}$ in dimethyl sulfoxide (DMSO, Sigma Chemical Co., St. Louis, Mo.) was rapidly diluted in $5 \mathrm{ml}$ of Hank's balanced salt solution (HBSS, KC Biological, Lenexa, Kans.) with vigorous vortexing to $2.5 \mu \mathrm{g} / \mathrm{ml}$ final concentration and added to the HSAB-immune lymph node cells. After $60 \mathrm{~min}$ incubation at $37^{\circ} \mathrm{C}$, the cells were washed in HBSS to remove unconjugated HSAB. Both PPD- and HSAB-immune lymph node cells were cultured at $2.5 \times 10^{6} / \mathrm{ml}$ in RPMI 1640 medium (M.A. Bioproducts, Walkersville, Md.) containing $300 \mu \mathrm{g} / \mathrm{ml}$ glutamine (KC Biological), 100 units/ml penicillin-streptomycin (KC Biological), $5 \times 10^{-5} M 2$-mercaptoethanol (Bio-Rad Laboratories, Richmond, Calif.), and 10\% heat-inactivated fetal calf serum (FCS, HyClone Laboratories, Logan, Utah) for 3 days and the blast cells harvested by centrifugation on Ficoll-Hypaque (Sigma Chemical Co.). The blasts were cultured

\footnotetext{
${ }^{3}$ Abbreviations used: $\alpha \mathrm{MM}, \alpha$-methylmannoside; ANB-NOS, $N$-5-azido-2-nitrobenzoyloxy succinimide; CAS, supernatant fluid from Con A-stimulated spleen cells; FCS, fetal calf serum; HSAB, $N$-hydroxysuccinimidyl 4-azidobenzoate; IL-2, interleukin 2; PBS, phosphate-buffered saline; PPD, purified protein derivative of tuberculin; Con $A$, concanavalin $A$.
} 
for an additional 2 days at 1 to $2 \times 10^{5} / \mathrm{ml}$ in medium containing $25 \%$ of supernatant fluid from conconavalin A (Con A, Miles-Yeda International, Elkhard, Ind.) stimulated rat spleen cells (CAS) and $0.1 \% \alpha$-methylmannoside ( $\alpha \mathrm{MM}$, Sigma). The resulting blast cells were fused with BW5147 cells (a generous gift from Dr. Ethan Shevach, Laboratory of Immunology, NIH) by established procedures $(9,10)$. The resulting hybridomas were screened with HSAB-conjugated Balb/c spleen cells or with untreated Balb/c spleen cells and $50 \mu \mathrm{g} / \mathrm{ml}$ of PPD for IL-2 production as described below. Those hybrids that showed HSAB or PPD-specific IL-2 production were further subcloned by limiting dilution. Both the HSAB-specific (5D10.1B8) and PPD-specific (8B2) T hybridomas showed genetic restrictions for $\mathrm{Ia}^{\mathrm{d}}$. All T-cell hybridomas were maintained in Dulbecco's modified Eagle medium (M.A. Bioproducts) containing glutamine, penicillin-streptomycin, 2-mercaptoethanol, 10\% nutrient cocktail (11), hypoxanthine, aminopterin, thymidine, and $15 \%$ heat-inactivated FCS.

Stimulator cell treatment. The various stimulator cells used in all of these experiments were Balb/c spleen cells, the $\mathrm{Ia}^{\mathrm{d}}$-positive B-cell lines A20.2JAd (a generous gift from Dr. Phillipa Marrack, National Jewish Hospital, Denver, Colo.), and LB 27.4 (obtained from Dr. David Shapiro, The University of Michigan Medical School), and the macrophage-like cell line $\mathrm{P}_{388 \mathrm{D}_{1}}$ (from Dr. P. Marrack). The $\mathrm{P}_{388 \mathrm{D}_{1} \text { were induced to }}$ express $\mathrm{Ia}^{\mathrm{d}}$ antigens as described before (12) by culture for 1 or 2 days in $25 \%$ CAS and $\alpha \mathrm{MM}$. The Ia content of these cells was determined by incubating $1 \times 10^{6}$ cells with $25 \lambda$ of supernatant fluid containing monoclonal antibody $17 / 227$ [ $\alpha$ Ia. 15 (a gift from Dr. John Niederhuber, The University of Michigan Medical School)] for $1 \mathrm{hr}$ at $4^{\circ} \mathrm{C}$. Following washing in PBS containing $0.02 \%$ sodium azide the cells were incubated for $1 \mathrm{hr}$ at $4{ }^{\circ} \mathrm{C}$ with $50 \lambda$ PBS azide containing $50,000 \mathrm{cpm}$ of ${ }^{125} \mathrm{I}$-protein A (a gift from Dr. Rod Nairn, The University of Michigan Medical School). The cells were washed to remove unbound ${ }^{125}$ I-protein $A$ and the cpm determined in a gamma counter. Uninduced $\mathrm{P}^{2} 88 \mathrm{D}_{1}$ showed some Ia expression by this assay, which was increased 5- to 10-fold after induction with CAS for 1 or 2 days, respectively. Cultured

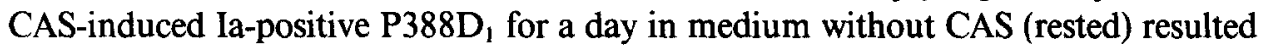
in a $60 \%$ reduction in Ia expression, which was reduced to background levels by 2 days. Operationally, for the purpose of this report, 1 or 2 day CAS-induced P388D will be referred to as Ia positive, while uninduced or induced and rested $\mathrm{P}_{388 \mathrm{D}_{1} \text { cells }}$ are referred to as functionally Ia negative.

For glutaraldehyde fixation, Ia-positive $\mathrm{P}_{388 \mathrm{D}_{1}}$ cells were washed in phosphatebuffered saline (PBS, pH 7.2) and treated by mixing for $15 \mathrm{sec}$ with $0.025,0.05$, or $0.1 \%$ glutaraldehyde (Sigma Chemical Co.) in PBS. The reaction was terminated by addition of excess PBS containing $0.1 \%$ glycine (Sigma Chemical Co.) and the cells washed $3 \times$ in HBSS prior to use as stimulator cells. All stimulator cells were treated with either HBSS alone (untreated controls) or with HBSS containing HSAB (20 or $40 \mu \mathrm{g} / \mathrm{ml}$ in most experiments) as described above and washed to remove unbound HSAB before addition to culture with $T$ cells.

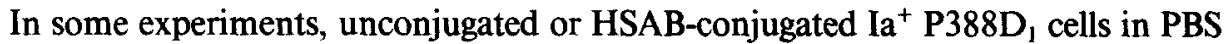
or HBSS were exposed in uncovered tubes or dishes for $15 \mathrm{sec}$ to a broad spectrum uv light to photoactivate the HSAB. As a control, the HSAB solution was exposed to uv light for $60 \mathrm{sec}$ prior to addition to the $\mathrm{Ia}^{+} \mathrm{P} 388 \mathrm{D}_{1}$ cells. In experiments to determine the cellular structures $\mathrm{HSAB}$ is conjugated to, $\mathrm{Ia}^{+}$or $\mathrm{Ia}^{-} \mathrm{P} 388 \mathrm{D}_{1}$ cells were coupled with 50 to $250 \mu \mathrm{Ci}{ }^{3} \mathrm{H}$-HSAB ( $50 \mathrm{Ci} / \mathrm{mmol}$, New England Nuclear, Boston, Mass.) as described above. The cells were left unlit or exposed to uv light, then solubilized 
in $0.5 \%$ Nonidet-P40, and the cell lysates examined for HSAB-coupled proteins and immunoprecipitation with anti-la.15 monoclonal antibody and analyzed by SDS-PAGE.

Assay of interleukin 2 (IL-2). The HSAB or PPD-specific T-cell hybridomas ( 1 to $2 \times 10^{5} /$ well) were cultured with $1 \times 10^{5}$ untreated or HSAB-treated stimulator cell lines, or $1 \times 10^{6}$ spleen cells, in hybridoma maintenance medium. In experiments with the PPD-specific hybridoma, no antigen or $10 \mu \mathrm{g} /$ well of soluble PPD was added to cultures with untreated stimulators. After $24 \mathrm{hr}$ of culture the supernatant fluid was removed and assayed for IL-2 with IL-2-dependent HT-2 cells (a generous gift from Dr. Ethan Shevach) as described elsewhere $(9,10)$. The greatest dilution of supernatant fluid maintaining $>90 \%$ HT-2 viability was the endpoint scored and the results expressed as IL-2 units/ml (12).

\section{RESULTS}

\section{Stimulator Cell Requirement of HSAB-Specific T-Cell Hybridomas}

The purpose in initiating these studies was to develop a system in which antigen could be coupled to the T-cell receptor and/or Ia antigens during the specific interaction. One way to accomplish this was to produce T-cell hybridomas directed against a photoactivatable antigen that could be induced to covalently couple to the T-cell receptor or Ia antigens during the cellular interactions with the APC. Accordingly, we produced T-cell hybridomas against HSAB-coupled APC. Although the HSAB-coupled self protein that provides the antigen determinant is not readily identified, it was reasoned that it is entirely unknown what happens to peptide and protein antigens upon processing, and to what self proteins these may become coupled. That is, in any antigen system, the final form of the antigen recognized by $T$ cells is completely unknown. Thus, the use of HSAB-coupled cells is no less defined than adding HSABconjugated peptides or proteins and HSAB-coupled cells offer the advantage that the specificity is likely to involve the HSAB molecule itself. The important criteria were that the T-cell response be genetically restricted by Ia antigens, and that the $T$ cells are specific for HSAB, and not some conformational change caused by conjugation. Accordingly, the genetic restrictions were determined by using HSAB-coupled spleen cells from genetically different mice as shown in Table 1. Results of this analysis indicate that the HSAB-specific response is most likely genetically restricted by the $K$ or I-A $\mathrm{A}^{\mathrm{d}}$ antigens. The ability of the response to be partially blocked with anti-I-A monoclonal antibodies (data not shown) and the failure of $\mathrm{K}^{\mathrm{d}}$ expressing cells to stimulate indicates that the response is genetically restricted by I-A ${ }^{\mathrm{d}}$. The fine specificity of the response was determined by comparing the ability of HSAB and ANB-NOS to stimulate the HSAB-specific T cells. ANB-NOS differs from HSAB solely by inclusion of a $\mathrm{NO}_{2}$ on the benzene ring, but couples identically to Lys in proteins through the reactive succinimide. Thus, if $\mathrm{T}$ cells were reacting only to protein conformation caused by conjugation, they would likely respond the same to HSAB and ANB-NOS. As shown in Table 2, the HSAB-specific T hybridoma cells responded only to HSAB and not ANB-NOS coupled spleen cells. This observation strongly suggests that the specificity of the HSAB response is directed in part against the benzene ring of the HSAB molecule, which also contains the azido group capable of forming covalent bends with adjacent structures upon exposure to light.

The next important task was to find a cell line capable of stimulating the HSAB- 
TABLE 1

Genetic Restrictions of Stimulation of HSAB-Specific T-Cell Hybridomas

\begin{tabular}{|c|c|c|c|c|c|}
\hline \multirow{2}{*}{$\begin{array}{l}\text { Spleen cells } \\
\text { from strain }{ }^{a}\end{array}$} & \multicolumn{4}{|c|}{$\mathrm{H}-2$} & \multirow[b]{2}{*}{ IL-2 units/m } \\
\hline & $\mathrm{K}$ & I-A & I-E & D & \\
\hline Balb/c & d & d & $\mathrm{d}$ & d & $>640$ \\
\hline $\mathrm{DBA} / 2$ & d & d & $\mathrm{d}$ & $\mathrm{d}$ & $>640$ \\
\hline D2.GD & $\mathrm{d}$ & d & b & $\mathrm{b}$ & $>640$ \\
\hline $\mathrm{A} / \mathrm{J}$ & $\mathrm{k}$ & $\mathrm{k}$ & $\mathrm{k}$ & d & $<20$ \\
\hline $\mathrm{B} 10 . \mathrm{S}(9 \mathrm{R})$ & $\mathbf{s}$ & $\mathbf{s}$ & $\mathrm{k}$ & $d$ & $<20$ \\
\hline B10.S & $\mathbf{s}$ & $\mathbf{s}$ & $\mathbf{s}$ & $\mathrm{s}$ & $<20$ \\
\hline B10.M & $\mathrm{f}$ & $\mathrm{f}$ & $f$ & $\mathbf{f}$ & $<20$ \\
\hline $\mathrm{C} 57 \mathrm{BL} / 6$ & $\mathrm{~b}$ & $\mathrm{~b}$ & $\mathrm{~b}$ & b & $<20$ \\
\hline
\end{tabular}

${ }^{a}$ Spleen cells from the mouse strains indicated were conjugated with HSAB $(10 \mu \mathrm{g} / \mathrm{ml})$, or left untreated, then cultured overnight with HSAB-specific T hybridoma cells and the IL-2 contained in the culture supernatant fluid was assessed as described under Materials and Methods. All cultures with unconjugated spleen cells contained $<20$ IL-2 units/ml.

specific T-hybridoma cells to provide a homogeneous source of APC. Initial experiments were therefore performed to determine if la-positive continuous cell lines could replace spleen cells as stimulator cells when directly conjugated with HSAB. To our surprise, it was found that HSAB-conjugated Ia-positive B-cell lines, A20.2JAD and LB.27.4, failed to stimulate IL-2 release by HSAB-specific T hybrids (Table 3). This lack of stimulatory activity did not reflect an inherent cellular defect since both B-cell lines presented PPD efficiently to a PPD-specific T hybridoma. In similar fashion P388D $D_{1}$ cells, a macrophage-like cell line, also failed to stimulate an HSAB-specific response. However, induction of Ia expression by culture of $\mathrm{P}^{388 \mathrm{D}_{1}}$ cells with CAS resulted in excellent T-cell stimulation following HSAB conjugation.

The failure of Ia-positive B-cell lines to stimulate HSAB responses could be due to several reasons: (1) B cells cannot process HSAB appropriately even following direct

TABLE 2

Specificity of the Anti-HSAB T-Cell Hybridoma Response

\begin{tabular}{cc}
\hline Spleen cell treatment $^{a}$ & IL-2 units/ml \\
\hline 0 & $<10$ \\
$\mathrm{HSAB}$ & \\
$20 \mu \mathrm{g} / \mathrm{ml}$ & 80 \\
$10 \mu \mathrm{g} / \mathrm{ml}$ & 80 \\
$5 \mu \mathrm{g} / \mathrm{ml}$ & 80 \\
$\mathrm{ANB}-\mathrm{NOS}$ & \\
$20 \mu \mathrm{g} / \mathrm{ml}$ & $<10$ \\
$10 \mu \mathrm{g} / \mathrm{ml}$ & $<10$ \\
$5 \mu \mathrm{g} / \mathrm{ml}$ & $<10$ \\
\hline
\end{tabular}

${ }^{a} \mathrm{Balb} / \mathrm{c}$ spleen cells were treated with HSAB or ANB-NOS at the indicated concentrations, then added to HSAB-specific T hybridomas and IL-2 production was measured as described under Materials and Methods. 


\section{TABLE 3}

The Ability of Various Cell Lines to Stimulate HSAB- or PPD-Specific T-Cell Hybridomas

\begin{tabular}{cccc} 
& & \multicolumn{2}{c}{$\begin{array}{c}\text { IL-2 units/ml } \\
\text { T-cell hybridoma specificity }\end{array}$} \\
\cline { 3 - 4 } Stimulator cell & Antigen & HSAB & PPD \\
\hline Balb/c spleen & - & $<20$ & $<20$ \\
A20-2JAd & + & 80 & 640 \\
& - & $<20$ & $<20$ \\
LB.27.4 & + & $<20$ & $>640$ \\
Ia $^{-}$P388D & - & $<20$ & $<20$ \\
& + & $<20$ & $>640$ \\
Ia $^{+}$P388D $_{1}$ & - & $<20$ & ND \\
& + & $<20$ & $<20$ \\
& - & 160 & 320 \\
\hline
\end{tabular}

${ }^{a}$ The indicated stimulator cells were either untreated, or HSAB treated for culture with HSAB-specific T hybridomas, or untreated and cultured with or without $10 \mu \mathrm{g} /$ well of PPD with the PPD-specific T-cell hybridomas as described under Materials and Methods. P388D $\mathrm{D}_{1}$ cells were induced for la expression $\left(\mathrm{Ia}^{+}\right)$ by culture for a day in CAS. Units/ml of IL-2 contained in the supernatant fluids of each culture were determined as described under Materials and Methods.

${ }^{b}$ Not determined.

chemical coupling of HSAB to the cell surface; (2) this HSAB-specific T-cell hybrid requires cofactors for IL-2 release that are provided by macrophages but not $B$ cells; or (3) the B-cell lines lack a surface structure that is present on P388D that becomes conjugated with HSAB and provides the relevant antigen. To discriminate between

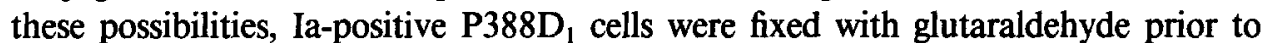
HSAB coupling and examined for their stimulatory capacity. As shown in Table 4, Ia-positive $\mathrm{P}_{388 \mathrm{D}_{1}}$ cells fixed with up to $0.1 \%$ glutaraldehyde then $\mathrm{HSAB}$ conjugated efficiently stimulated HSAB-specific $\mathrm{T}$ hybrids. The effectiveness of glutaraldehyde

TABLE 4

The Ability of Glutaraldehyde-Fixed Cells to Stimulate HSAB- and PPD-Specific T-Cell Hybridomas

\begin{tabular}{ccr}
\hline & \multicolumn{2}{c}{$\begin{array}{c}\text { IL-2 units/ml } \\
\text { T-cell hybridoma specificity }\end{array}$} \\
\cline { 2 - 3 } $\begin{array}{c}\text { Glutaraldehyde } \\
\text { treatment }\end{array}$ & HSAB & PPD \\
\hline 0 & 640 & 10,240 \\
0.025 & 640 & 40 \\
0.05 & 640 & $<20$ \\
0.1 & 320 & $<20$ \\
\hline
\end{tabular}

${ }^{a} \mathrm{P}_{388 \mathrm{D}_{1}}$ cells cultured for 2 days with CAS (Ia-positive) were treated with $0,0.025 \%, 0.05 \%$, or $0.1 \%$ glutaraldehyde then conjugated with $40 \mu \mathrm{g} / \mathrm{ml}$ of HSAB or added to culture with $10 \mu \mathrm{g} / \mathrm{well}$ of PPD for stimulation of HSAB- or PPD-specific T hybridomas, respectively. IL-2 activity contained in the culture supernatant fluids was determined as described under Materials and Methods. IL-2 activity in cultures without antigen was $<20$ units/ml for both $\mathrm{T}$ hybrids. 
fixation was shown by the failure of the fixed cells to process and present PPD, as has been shown with other peptide antigens (13). These results suggest that the inability of HSAB-conjugated B-cell lines is not due to released cofactors (although surfacebound cofactors cannot be excluded), and that HSAB processing is not required for antigen presentation. Therefore, the more likely explanation for the inability of HSABconjugated B-cell lines to stimulate is that they lack a particular surface structure

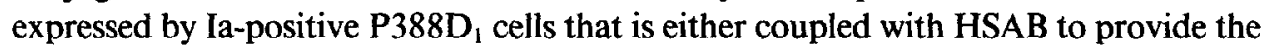
relevant antigen or is otherwise important in recognition. However, since these B-cell lines express Ia, the structure to which HSAB couples is most likely not Ia.

\section{Modulation of Ia on the Stimulatory Capacity of HSAB-Conjugated P388D, Cells}

The experiments described above suggest that the antigen recognized by the HSABspecific hybridoma is not simply Ia antigens coupled with HSAB. To investigate this in a more rigorous fashion, functionally Ia-negative $\mathrm{P} 388 \mathrm{D}_{1}$ cells were conjugated with HSAB then incubated with CAS to induce Ia expression to determine if the relevant structure to which HSAB coupled was expressed in the absence of Ia. As shown in Table 5 , HSAB-conjugated Ia-negative $P 388 D_{1}$ cells that were subsequently induced to express Ia stimulated HSAB T-cell hybrid responses as well as direct HSAB

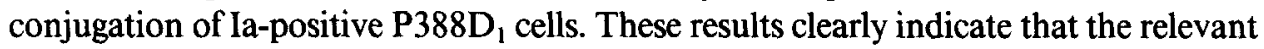
antigen is not HSAB-coupled Ia and that the responsible surface structure is expressed independently of Ia.

One of the interesting possibilities raised by this experiment is that Ia and the HSABcoupled surface structure may not be tightly physically linked and can be independently modulated. As noted in the above experiment (Table 5, Group 2), Ia-positive P388D cells that are cultured for a day in the absence of CAS become functionally Ia negative and fail to stimulate HSAB responses. Taking advantage of this observation, it was possible to modulate Ia antigen expression to determine if Ia physically combined

\section{TABLE 5}

Stimulatory Capacity of HSAB-Conjugated Ia-Negative P388D 1 Cells upon Subsequent Induction of Ia Expression

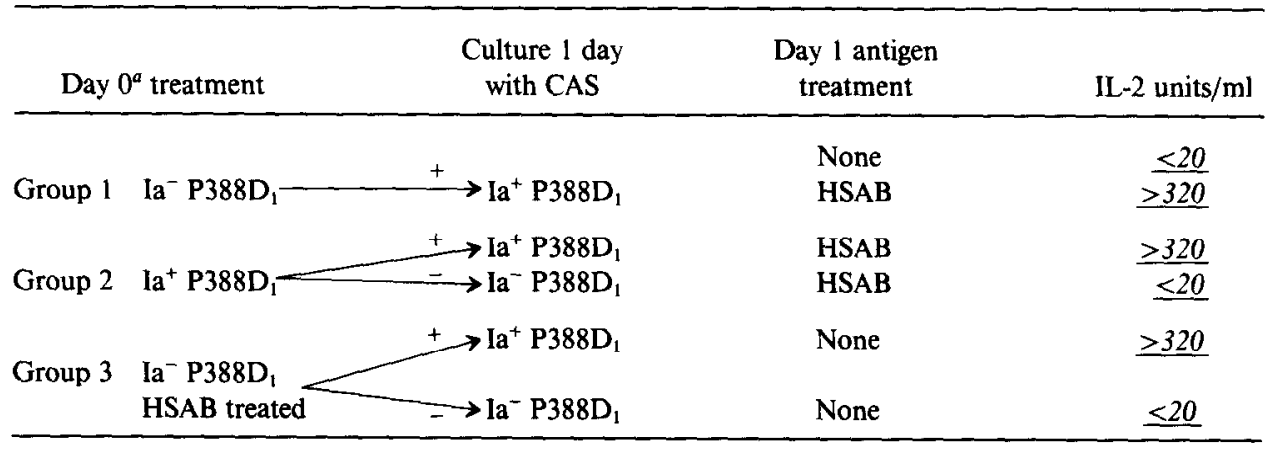

\footnotetext{
${ }^{a}$ Ia-negative P388D 1 that were untreated (Group 1) or HSAB conjugated (Group 3), or 1 day CASinduced Ia-positive P388D, (Group 2), were cultured for a day in the presence $(+)$ or absence $(-$ ) of CAS and $\alpha \mathrm{MM}$. The washed cells were either left untreated or treated with $40 \mu \mathrm{g} / \mathrm{ml}$ of $\mathrm{HSAB}$ as indicated then cultured for a day with HSAB T hybrids. The IL-2 units/ml contained in each culture supernatant were determined as described under Materials and Methods.
} 
with the HSAB-coupled structure and removed this structure when Ia was lost from the cell. Accordingly, Ia-negative or la-positive $\mathrm{P}_{388 \mathrm{D}_{1}}$ were conjugated with $\mathrm{HSAB}$, then incubated in the presence or absence of CAS for a day; then each of these groups was cultured for an additional day with or without CAS. At each time all groups were tested for their ability to stimulate HSAB-specific $T$ hybrids without additional HSAB treatment. As shown in Table 6, HSAB-conjugated Ia-positive P388D, lost their ability to stimulate when Ia was lost, but regained their stimulatory capacity when Ia was subsequently reexpressed. Thus, antigen is not removed from the cell concomitant with the loss of Ia, but remains such that the cell can again stimulate when Ia is

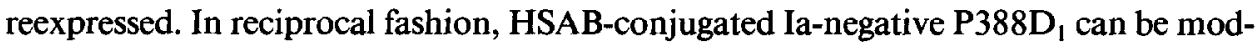
ulated to express and lose Ia and retain the relevant antigen to present whenever Ia is present. These experiments show that Ia and antigen can be separately modulated.

A number of other biochemical experiments were performed to determine if HSAB was either directly conjugated to Ia, or was close enough to Ia to be crosslinked when exposed to uv light. Unfortunately, all of these results were negative (data not shown) and anti-Ia antibody failed to immunoprecipitate any ${ }^{3} \mathrm{H}-\mathrm{HSAB}$ associated with Ia from coupled Ia-positive $\mathrm{P}_{388 \mathrm{D}_{1}}$ that were either unlit or exposed to uv light. These results are consistent with the functional results described above indicating that the HSAB is not coupled to Ia. Of interest, ${ }^{3} \mathrm{H}$-HSAB couples to 17 to 22 discrete cellular structures on Ia-positive or Ia-negative P388D $\mathrm{D}_{1}$ cells (the pattern is identical for both) of molecular weights of between 40 and $100 \mathrm{~K}$. Upon exposure to light, this pattern

TABLE 6

Effect of Gain and Loss of Ia Antigens on the Stimulatory Capacity of HSAB-Conjugated P388D, Cells

\begin{tabular}{|c|c|c|c|c|c|c|}
\hline \multicolumn{2}{|c|}{ Day $0^{\alpha}$ treatment } & $\begin{array}{c}\text { Day 0 } \\
\text { IL-2 units } / \mathrm{ml}\end{array}$ & $\begin{array}{c}\text { Culture day } 1 \\
\text { with CAS }\end{array}$ & $\begin{array}{c}\text { Day } 1 \\
\text { IL-2 units/ml }\end{array}$ & $\begin{array}{c}\text { Culture } \\
\text { day } 2 \text { with } \\
\text { CAS }\end{array}$ & $\begin{array}{c}\text { Day } 2 \\
\text { IL-2 units/ml }\end{array}$ \\
\hline \multirow{3}{*}{$\mathrm{Ia}^{-} \mathrm{P} 388 \mathrm{D}_{1}$} & None & $\leq 20$ & & & & \\
\hline & HSAB & $<20$ & $\mathrm{Ia}^{-}$P388D & & & $\leq \leq 0$ \\
\hline & & & $\mathrm{Ia}^{+} \mathrm{P} 388 \mathrm{D}_{1}$ & $\underline{640}$ & $\begin{array}{l}\mathrm{Ia}^{-} \text {P388D } \\
\mathrm{Ia}^{+} \text {P388D }\end{array}$ & $\frac{<20}{\underline{320}}$ \\
\hline \multirow{3}{*}{$\mathrm{Ia}^{+} \mathrm{P} 388 \mathrm{D}_{1}$} & None & $\leq 20$ & & & & \\
\hline & & 160 & $\mathrm{Ia}^{-} \mathrm{P} 388 \mathrm{D}_{1}$ & $<20$ & & \\
\hline & & & $\mathrm{Ia}^{+}$P388D & $\underline{1280}>$ & $\begin{array}{l}\mathrm{Ia}^{-} \text {P388D } \\
\mathrm{Ia}^{+} \text {P388D }\end{array}$ & $\underline{\leq 20}$ \\
\hline
\end{tabular}

\footnotetext{
${ }^{a}$ The design of this experiment is similar to that described in the legend for Table 5. Ia-negative or 1 day CAS-induced Ia-positive P388D $\mathrm{D}_{1}$ cells were left untreated or treated with $40 \mu \mathrm{g} / \mathrm{ml} \mathrm{HSAB}$ on Day 0 . The HSAB-conjugated cells were then cultured for a day (Day 1) with or without CAS, then each of these groups cultured for an additional day (Day 2) with or without CAS as indicated. It should be noted that cells were never exposed to HSAB after initial conjugation on Day 0 . Aliquots of cells from each stimulator treatment group on Days 0,1 , or 2 were tested for stimulatory activity by culture for a day with HSAB-specific Thybridoma cells. IL-2 units/ml for each group on the day indicated were determined as described under Materials and Methods.
} 
of bands is unaltered and no higher mol wt aggregates are formed by HSAB crosslinking. This is not surprising since HSAB is a small molecule and would only crosslink structures that are very closely associated (within around $6 \AA$ ) on the membrane. It would therefore be expected that upon exposure to uv, HSAB under these conditions would crosslink mainly, if not entirely, to the structure to which it is chemically coupled. This is an important point to consider when interpreting the experiments described below.

\section{Specific Photoelimination of the HSAB Antigenic Determinant}

Since the primary feature of the HSAB system is to provide a photoactivatable antigen, it was important to determine what effect light had on the HSAB-antigenic

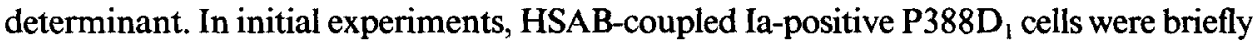
exposed to light to activate the HSAB and determine if this altered antigenicity. As shown in Table 7, lighting of HSAB-coupled cells eliminated their stimulatory capacity. This effect was seemingly specific since exposure of Ia-positive P388D, cells to light prior to HSAB conjugation had no effect on their stimulatory capacity. Of interest is the observation that lighting HSAB prior to incubation with Ia-positive $\mathrm{P}_{388 \mathrm{D}_{1} \text { cells }}$ likewise has no effect on stimulation. This suggests that the HSAB-specific T cells are not highly specific for the azido group, and that elimination of antigenicity by lighting is not due to direct effects on HSAB, but rather results from some crosslinking reaction. However, it could not be determined if lighting of HSAB-coupled Ia-positive P388D cells was a nonspecific result of HSAB crosslinking on that cell. To examine this, HSAB-coupled Ia-positive $\mathrm{P}_{388 \mathrm{D}_{1}}$ were exposed to light and added to culture with PPD and PPD-specific T-hybridoma cells. If crosslinking by HSAB was nonspecifically inhibitory, then the cells would be unable to stimulate a PPD-specific response. As shown in Table 8, lighting of HSAB-coupled Ia-positive $\mathrm{P}_{388 \mathrm{D}_{1}}$ cells dramatically inhibited the stimulation of the HSAB-specific response, but had no effect on stimulation of the PPD-specific response. This result indicates that the effects of uv light selectively eliminate only the HSAB antigen on the surface of the APC and do not interfere with their stimulatory capacity. In other experiments (data not shown) culture of HSAB-coupled APC for 0 to $18 \mathrm{hr}$ after conjugation (to allow any new molecular associations to occur) then exposing them to light, or not, showed that the HSABantigenic determinant was photosensitive at all time points tested. Thus, new associations with HSAB-coupled membrane structures, if they occur, does not change the

TABLE 7

Elimination of T-Cell Stimulation by Lighting HSAB-Conjugated Antigen-Presenting Cells

\begin{tabular}{clc}
\hline \multicolumn{2}{c}{ Antigen-presenting cell treatment ${ }^{a}$} & IL-2 units/ml \\
\hline Group 1 & $\mathrm{Ia}^{+}$P388D $\rightarrow$ HSAB & $>640$ \\
Group 2 & $\mathrm{Ia}^{+}$P388D $\rightarrow$ HSAB $\rightarrow$ Lit & $<20$ \\
Group 3 & $\mathrm{Lit} \mathrm{Ia}^{+}$P388d $_{1} \rightarrow$ HSAB & $>640$ \\
Group 4 & $\mathrm{Ia}^{+}$P388D $\rightarrow$ Lit HSAB & $>640$ \\
\hline
\end{tabular}

\footnotetext{
${ }^{a}$ Unlit or lit (Group 3) $\mathrm{Ia}^{+} \mathrm{P} 388 \mathrm{D}_{1}$ were conjugated with the photoactivatable antigen HSAB, either unlit or lit (Group 4), and the HSAB-coupled cells were left unlit or exposed to light (lit, Group 2) and added to culture with HSAB-specific T-cell hybridomas as described under Materials and Methods.
} 
TABLE 8

Specificity of Lighting on Elimination of Antigenicity by the Photoactivatable HSAB Antigen

\begin{tabular}{|c|c|c|}
\hline \multirow[b]{2}{*}{ Antigen-presenting cell treatment ${ }^{a}$} & \multicolumn{2}{|c|}{$\begin{array}{c}\text { IL-2 units/ml by T-cell } \\
\text { hybridomas directed } \\
\text { against }\end{array}$} \\
\hline & IISAB & PPD \\
\hline Group $1 \quad \mathrm{Ia}^{+} \mathrm{P} 388 \mathrm{D}_{\mathrm{t}}$ & $<20$ & $<20$ \\
\hline Group $2 \mathrm{Ia}^{+} \mathrm{P}^{288 \mathrm{D}_{1}} \rightarrow$ HSAB & $>640$ & ND \\
\hline Group $3 \mathrm{Ia}^{+} \mathrm{P}^{388 \mathrm{D}_{1}} \rightarrow \mathrm{PPD}$ & $\mathrm{ND}^{b}$ & 320 \\
\hline Group $4 \quad \mathrm{Ia}^{+}$P388D $\rightarrow$ HSAB $\rightarrow$ PPD & $>640$ & 320 \\
\hline Group $5 \mathrm{Ia}^{+}$P388D $_{1} \rightarrow$ HSAB $\rightarrow$ Lit $\rightarrow$ PPD & 40 & 320 \\
\hline
\end{tabular}

${ }^{a}$ Untreated or HSAB-conjugated $(10 \mu / \mathrm{ml}) \mathrm{Ia}^{+} \mathrm{P} 388 \mathrm{D}_{1}$ cells were cultured with or without soluble PPD $(10 \mu \mathrm{g})$ and HSAB-specific or PPD-specific T-cell hybridoma cells. In Group 5 the HSAB-coupled cells were exposed to light before the addition of PPD and T cells.

${ }^{b}$ Not determined.

ability of light to inactivate the HSAB determinant, presumably by crosslinking. As discussed above, this crosslinking of HSAB with light is most likely with the same structure to which it is chemically coupled.

\section{DISCUSSION}

The purpose of this report is to describe a T-cell antigen-presenting cell system utilizing a photoactivatable crosslinking antigen to help identify the antigen-specific recognition complex. Several interesting findings were observed that are of importance to understanding antigen presentation. The first observation is that HSAB-coupled Ia does not seem to provide the antigenic determinant recognized by the HSAB-specific $T$ cells. This was demonstrated in several ways. The first is that Ia-positive B-cell lines, which present a variety of antigens $(4,13)$, fail to stimulate HSAB T hybrids even when HSAB is chemically coupled to their surface. If HSAB-conjugated Ia provided the relevant antigen, then these Ia-positive cells would have been efficient stimulators. The second is that HSAB coupled Ia-negative $\mathbf{P}_{388 D_{1}}$ cells are efficient stimulators if Ia expression is induced at a later time. In this instance it is clear that the antigenically relevant surface structure is present prior to Ia expression and is not provided by direct conjugation to Ia. Moreover, glutaraldehyde fixed Ia-positive P388D treated with HSAB are efficient stimulators ruling out the necessity for HSAB antigen processing or a cofactor requirement for stimulation of the HSAB T hybrids. Third, immuno-

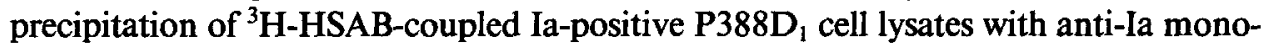
clonal antibodies failed to demonstrate any Ia-associated antigen. Taken together, these results indicate that the relevant antigen recognized by these $T$ cells consists of HSAB coupled to some non-Ia surface structure present on $P 388 D_{1}$ macrophage-like cells. This is of interest since other recent studies (14) have suggested that exogenous antigen is intimately associated with cellular Ia antigens. In addition, in other systems employing TNP conjugation of stimulator or target cells it was suggested that directly TNP modified MHC antigens provided the relevant antigen recognized by $T$ cells $(15,16)$. However, little direct TNP modification of MHC antigens was found following 
conjugation to guinea pig macrophages and it was speculated that the relevant T-cell antigen in this case was TNP coupled to another membrane constituent (17). In this system it was also found that TNP coupled glutaraldehyde-fixed macrophages were efficient stimulators ruling out the necessity for antigen processing (18), as reported here for HSAB.

The observation that HSAB-specific T hybridomas are stimulated only by the Iapositive macrophage-like cell line and not by the Ia-positive B-cell lines is also of interest. One explanation for this may be that the Ia expressed by both cell types is slightly different, either in primary sequence or in modifications such as glycosylation (19), and that the $T$ cells are specific for a particular form of Ia. This does not seem likely, though, since many T-cell hybridomas restricted to I- $\mathrm{A}^{\mathrm{d}}$ are stimulated by both A20 and Ia-positive P388D $D_{1}$ cells, as shown here with the PPD-specific hybrids. Another possibility is that the B-cell lines lack the relevant surface structure expressed by macrophages that is coupled by HSAB to provide the T-cell antigen. This is a distinct possibility, although SDS-PAGE analysis of the surface structures coupled with ${ }^{3} \mathrm{H}$ $\mathrm{HSAB}$ on $\mathrm{A} 20$ and $\mathrm{P}_{388 \mathrm{D}_{1}}$ cells showed no apparent differences. A third possibility is that this $\mathrm{T}$-cell hybrid may require another macrophage structure for activation that is absent from B cells and for this reason is "macrophage-specific."

Another unique feature of the antigen system examined here is the photosensitivity of the HSAB antigenic determinant. Thus, at any time after HSAB coupling, exposure of the APC to light selectively and specifically eliminates their ability to stimulate the HSAB-specific T-cell hybridomas. Since the T cells show specificity for the benzene ring of the molecule, the most likely explanation for this is that light causes HSAB to covalently crosslink to some APC surface and thereby obscure the determinant bound by the antigen-specific $T$-cell receptor. If this is the case, then the photoreactive end of the chemically coupled HSAB must be very close to structures it can crosslink to. Since SDS-PAGE analysis showed that lighting of ${ }^{3} \mathrm{H}-\mathrm{HSAB}-\mathrm{coupled}$ cells caused no detectable aggregation, nor any associations with Ia, the most likely explanation is that upon lighting $\mathrm{HSAB}$ crosslinked with the same structure to which it was already chemically bound. This seems most likely given the small size of the HSAB molecule allowing crosslinking of only structures that are extremely close to the HSAB. Thus, crosslinking of the structure by HSAB causes the antigenic determinant to be "locked in" such that it cannot be bound by the T-cell receptor. The implication of this is that the T-cell receptor must physically contact the HSAB molecule. Thus, this system may provide an excellent opportunity to directly crosslink the HSAB-coupled APC structures and the $\mathrm{T}$-cell receptor to directly determine the cellular structures involved in specific interactions with antigen.

If the $\mathrm{T}$ cells recognize the HSAB antigen in association with Ia, it must involve a mechanism to bring these two elements together. There are several ways by which this might occur. The first would be a variation of the determinant selection model in which antigen (HSAB coupled non-MHC membrane proteins) is bound to la and that this complex is recognized by the T-cell receptor $(7,8)$. Alternatively, Ia and the antigenically relevant membrane structure may be only loosely organized in proximity in the membrane without any particular additional interaction caused by HSAB conjugation. The $T$ cell would then cause the Ia and HSAB antigen to become physically associated for recognition as a single determinant by the $T$ receptor (The Induced Fit Hypothesis, 20). Alternatively, recognition of the HSAB antigen and Ia may be unique events. These mechanisms will be tested in the future by photocrosslinking the HSAB 
antigen to the structures with which it interacts during the antigen-specific T-cellAPC cell interactions. This should allow determination if antigen associates with Ia only in the presence of $\mathrm{T}$ cells, or if $\mathrm{T}$-cell receptor binding of antigen is distinct from recognition of Ia.

\section{ACKNOWLEDGMENT}

The authors thank Ms. Emma Williams for the excellent typing of this manuscript.

\section{REFERENCES}

1. Unanue, E. R., Adv. Immunol. 31, 1, 1981.

2. Stingl, G., Katz, S. I., Clement, L., Green, I., and Shevach, E. M., J. Immunol. 121, $2005,1978$.

3. Chestnut, R., Cohn, S., and Grey, H. M., J. Immunol. 128, 1764, 1982.

4. Walker, E., Warner, N., Chestnut, R., Kappler, J., and Marrach, P., J. Immunol. 128, 2164, 1982.

5. Steinman, R. M., and Nussenzweig, M. C., Immunol. Rev. 53, 125, 1980.

6. Malissen, B., Price, M. P., Goverman, J. M., McMillan, M., White, J., Kappler, J., Marrack, P., Pierres, A., Pierres, M., and Hood, L., Cell 36, 319, 1984.

7. Rosenthal, A. S., Immunol. Rev. 40, 136, 1978.

8. Benacerraf, B., J. Immunol. 120, 1809, 1978.

9. Kappler, J. W., Skidmore, B., White, J., and Marrack, P., J. Exp. Med. 153, 1198, 1981.

10. Glimcher, L. H., and Shevach, E. M., J. Exp. Med. 156, 640, 1982.

11. Mishell, R. I., and Dutton, R. W., J. Exp. Med. 126, 423, 1967.

12. Zlotnik, A., Shimonkevitz, R. P., Gefter, M. L., Kappler, J., and Marrack, P., J. Immunol. 131, 2814, 1983.

13. Shimonkevitz, R., Kappler, J., Marrack, P., and Grey, H., J. Exp. Med. 158, 303, 1983.

14. Matis, L. A., Glimcher, L. H., Paul, W. E., and Schwartz, R. H., Proc. Natl. Acad. Sci. USA 80, 6019, 1983.

15. Vitetta, E. S., Hart, D. A., and Forman, J., J. Immunol. 121, 997, 1978.

16. Forman, J., and Vitetta, E. S., J. Immunol. 121, 1002, 1978.

17. Clement, L. T., Thomas, D. W., Kask, A. M., and Shevach, E. M., Nature (London) 274, 592, 1978.

18. Thomas, D. W., J. Immunol. 121, 1760, 1978.

19. Cullen, S. E., Kindle, C. S., Shreffler, D. C., and Cowing, C., J. Immunal. 127, 1478, 1981.

20. Thomas, D. W., J. Theor. Biol, in press. 